\title{
SPATIAL ETHICS AS AN EVALUATION TOOL FOR THE LONG-TERM IMPACTS OF MEGA URBAN PROJECTS: AN APPLICATION OF SPATIAL ETHICS MULTI-CRITERIA ASSESSMENT TO CANNING TOWN REGENERATION PROJECTS, LONDON
}

\author{
JUHYUN LEE \\ The Bartlett School of Planning, UCL, UK.
}

\begin{abstract}
Decision-making processes for mega urban infrastructure developments are far from closed rational systems. They rarely satisfy everyone, and are politically driven, reflecting the interests of key stakeholders and macro-scale economic development goals, with limited evaluation of multi-scale impacts and unwanted negative consequences to society at large. An integrated approach to evaluating impacts is required in consideration of the spatial and thus unavoidably ethical, political nature of decisionmaking on mega infrastructure development. Spatial Ethics (SE) is addressed as a conceptual basis to investigate the multi-scale impacts and the spatial equity issues of urban infrastructure development. SE multi-criteria assessment (MCA) has been explored as a tool to evaluate urban transport projects in respect of plurality of actors, interests and priorities by involving stakeholders in shaping the framework as well as evaluating the impacts. A case study, which applies the framework, identifies that urban transport infrastructure investment brings benefits and costs related to urban spatial transformation. The positive return to society over time and space is limited from the spatially ethical perspective; however, identification of winners and losers cannot be generalized as the impacts are perceived differently by individuals who are affected by various external and internal factors.

Keywords: decision-making, long-term impacts, multi-criteria assessment, social impact, spatial ethics, urban regeneration, urban transport infrastructure investment.
\end{abstract}

\section{INTRODUCTION}

The question that drives this research is 'does urban investment bring positive returns to society over time and space, and if so how?' Mega infrastructures are seen as catalysts in the process of strategic change, urban and regional (re) development, and nation-building, providing step changes in connectivity and production that support the development of society and the economy [2]. Emphasis has been placed mainly on the positive contributions of such investment, while negative impacts generated over time and space are often downplayed in decision-making, despite significant criticism from the perspectives of public benefits, urban spatial justice, local sustainability, and, amongst others. With a prevailing policy and decision-making process that is politically driven and commonly in favour of efficient economic growth via market mechanisms, the importance of certain types and scales of project impacts is not well discussed nor measured through the appraisal and the delivery of such projects. Infrastructure investment appraisal tends to focus on monetizing a limited range of effects of projects, applying top down, economically focused approaches to ex-ante evaluation, and neglecting long-term social and environmental consequences.

This research aims at developing an integrated framework to examine urban spatial transformation that accounts for multi-scale impacts. It examines Spatial Ethics (SE) as a theoretical and methodological basis for long-term impact evaluation, which sees planning as an applied ethics to be shaped not only by economic values, but also ethical ones directed 
towards achieving balanced spatial development [1]. The concept is translated into a conceptual framework and integrated evaluation tool, and applied to an actual case, Canning Town in London, to show a working example of how the evaluation can promote the ethically sound and integrated development of urban space. Impact evaluation conducts a mixed assessment, which draws on observation, interview, and survey data analysis.

\section{IMPACT EVALUATION WITH RESPECT TO MEGA INFRASTRUCTURE INVESTMENT FOR URBAN REGENERATION}

\subsection{Mega urban transport infrastructure for urban regeneration: public interest, spatial equity and local sustainability}

Decision-making in mega transport infrastructure is influenced by national, regional and local contexts, as well as the political ideology of the decision-makers [2]. With the impact of neoliberal ideology on government and public service delivery, and a reliance on partnerships with private sectors in an era of fiscal constraint, the goal of enhancing public interests is often not prioritized during decision-making processes and delivery phase, despite arguments suggesting that urban space and facilities need to be managed in a way that represents society in its entirety $[3,4]$. The construction of highly capable infrastructures is seen as being of strategic importance in spatially selective areas, whilst other parts of the city may be neglected with deteriorating public infrastructure [5]. Preferred ways of increasing the efficiency of investment tend to include cutting short-term financial costs in favour of finding ostensibly 'innovative' ways to meet narrowly conceived objectives, which in turn, can result in considerable negative externalities borne by the public.

Attention paid to the social-spatial impacts of transport has increased in policy discourses over the past decade. Levinson [6] argues that any new transportation project or policy creates both winners and losers from the standpoints of mobility, accessibility, and environmental and economic concerns. Urban transport infrastructures for urban regeneration often do not accommodate both fairness and equity in the physical and geographical distribution of goods, accessibility for people, and distribution of other gains such as increases in land and property prices [7, 8]. In addition, transformations of urban spaces and urban economies as a result of mega transport projects have unequal impacts concerning land-use change over long-term periods [9]. Burdens and exposure to social and environmental risks also bring spatially differential impacts [10].

It is argued that mega urban projects are still based on demand and activities forecasts, not on the actual needs in the neighbourhood of urban regeneration [11]. The local sustainability concept has been addressed to understand impacts that mega urban infrastructure investment generates on the communities and neighborhoods. It is based on traditional social policy areas and the notions of happiness and quality of life such as education, housing and environmental health, as well as in identity and sense of place, and social cohesion across multiple spatial scales including household, community, city, region and nation [12].

\subsection{Issues of impact evaluation of mega urban projects}

Discussion of the impacts of imperfect market mechanisms, the irrationality of decisionmaking, and the other issues is lacking in the content of current evaluation tools [13]. Social issues and micro scale impacts rarely feature prominently on the agenda of decision-makers 
and are often subordinated to macro-economic growth [1, 14]. Most impact assessments involve the aggregation of impacts no matter who benefits or loses, where people benefit or lose, and to what extent. For measuring local sustainability, it is often the case that inadequate indicators and poor or under-resourced data collection methods obscure the real impact [15]. It is also difficult to attribute observed outcomes to specific programs.

A few alternative approaches have been discussed and used. Social Impact Assessment (SIA) has been measuring the socio-cultural consequences of projects that alter ways in which people live, work, and play by different groups [16]. Some of key measures include social equity and distributional effects, and impacts on vulnerable groups. Critically, it distinguishes 'social changes' and 'social impacts' by measuring the pattern of social change such as physical segregation first, then identifying impacts including well-being [17]. Furthermore, Local Sustainability Assessment (LSA) has been discussed within the context of calls for the robust appraisal of policies, programmes, plans and projects against sustainability criteria at the local scale. It emphasizes the importance of governance and local contexts in devising and using indicators to discern clear links between the development of an indicator and actual changes in the outcomes of projects and programmes [15].

Multi-criteria assessment (MCA) for the appraisal of infrastructure has been promoted in comparison with CBA, permitting a wide set of objectives to be assessed [2]. It allows both quantified and non-quantified criteria of project outputs, outcomes and impacts to be set out together in a common framework. Importantly, MCA needs to be undertaken by a group of key stakeholders, through dialogue, who shape the formulation of criteria and relevant project performance data, and conduct their own assessments [2].

\section{SPATIAL ETHICS MULTI-CRITERIA ASSESSMENT (SE MCA)}

Firstly, Spatial Ethics is explored as a conceptual basis to shape a multi-criteria evaluation framework to investigate the long-term impacts of mega urban infrastructure investment. Secondly, a basic framework of Spatial Ethics Evaluation is defined: key dimensions of Spatial Ethics will be shaped into a basic framework with SE measurement criteria. Thirdly, a brief process of application of the Spatial Ethics MCA framework into a case will be identified.

\subsection{Four dimensions of Spatial Ethics (SE) for long-term impact evaluation}

Spatial Ethics offer a holistic view and approach to achieving balanced spatial development, recognizing that planning needs to be understood fundamentally as spatial ethics, a form of applied ethics [1, 4, 18, 19]. Fisher ([13]) identifies four dimensions of SE, which can be referred to as a basis for decision-making of spatial planning and urban development (see Fig. 1).

Virtuous space, based on the Aristotelian approach to ethics, addresses the ethical characteristics of space including connectivity, integration and inclusiveness in urban space. Contractual space, which emerges from the social contracts ethics of Hobbes and Rousseau, highlights the important role of space to the public and society in keeping the peace and avoiding conflicts. Dutiful space respects the golden rule of the Kantian approach; it stresses the duty of examining the impacts of creating or using space for the needs or ends of a much larger number, especially those who may never encounter spaces being created. Finally, consequential space focuses on maximizing the long-term return on investment in space, benefiting the needs of the greatest number. 


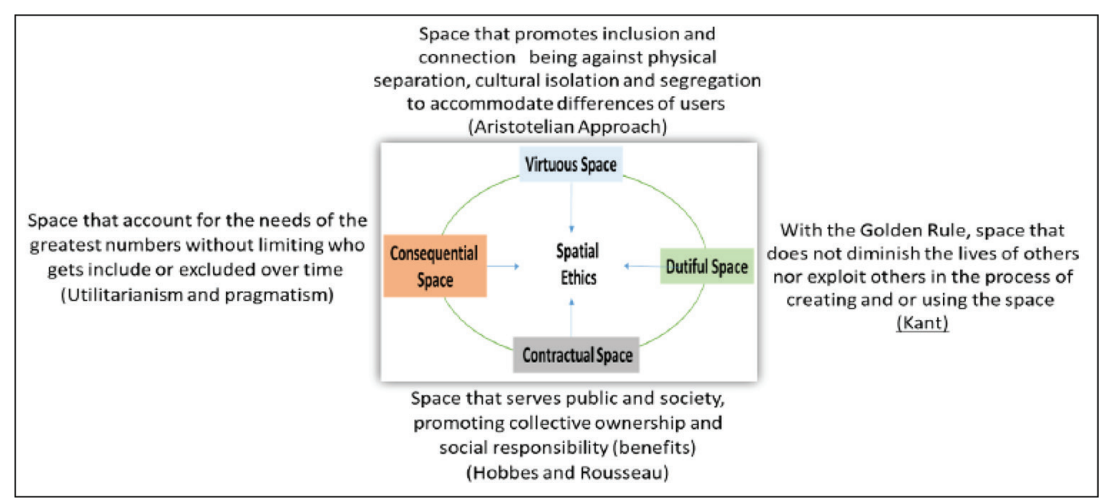

Figure 1: Four dimensions of Spatial Ethics. Source: adopted from Fisher (2009).

\subsection{Developing the basic framework for Spatial Ethics Evaluation (SEE)}

To operationalize the four SE dimensions (Fig. 1), a basic framework has been developed for SEE (see Table 1). Firstly, key values for each of the four dimensions of Spatial Ethics are related to some of the critical impacts and outcomes of mega infrastructure investment, in particular urban transport infrastructure for urban regeneration projects. Secondly, the domains and the sub-domains of the Spatial Ethics Framework are defined and shaped into four objectives and nine sub-objectives, based on which impacts of mega infrastructure projects are measured as they relate to Spatial Ethics (Table 1). Secondly, SE criteria need to be identified to serve as the performance measures of the operational objectives of the multicriteria framework. Criteria from other evaluation frameworks, which afford clear pictures of the multiple criteria mostly associated with assessing progress toward achieving four domains of Special Ethics, can be referred to. Considered here include a few appraisal frameworks which measure the land use impact of transport, outcome quality of urban spaces, transport sustainability and equity, and local sustainability of urban regeneration.

The contribution of mega urban transport investment (MUTI)'s impact to society, which will be measured, includes (i) the integration of space and communities, as well as the inclusiveness of spaces being created, making positive socioeconomic impacts on society; (ii) enhancing the value of public goods, which bring social and economic vibrancy to society, meeting common (social) interests and needs for urban spaces; (iii) the fair and equitable distribution of benefits of MUTI, which refer to good accessibility to transport and opportunities, and the regeneration effects at a local (micro) scale, the mitigation of negative externalities, and the obviation of economic and social disparities between the least and most disadvantage areas; and (iv) the contribution to the quality of life of local communities by bringing positive changes to everyday life.

To apply SEE into MUTI projects through MCA, three phases of MCA development and application processes (i.e. problem defining, model building, and model use) are adopted to specify how well the performance of investment projects contributes to the key values of SE expressed by the criteria. Based on the assessment of the results, scores can be derived by researchers and/or key stakeholders. 
Table 1: Domains (objectives) and sub-domains (sub-objectives) of Spatial Ethics.

\begin{tabular}{|c|c|c|}
\hline \multicolumn{2}{|c|}{ Domains (Objectives) } & \multirow{2}{*}{$\begin{array}{l}\text { Sub-domains (Sub-objectives) } \\
\text { To foster the integration and the connection } \\
\text { of physical space and communities, reducing } \\
\text { segregation; } \\
\text { To ensure the inclusiveness and the openness of } \\
\text { space, meeting needs of various users }\end{array}$} \\
\hline $\begin{array}{l}\text { Virtuous } \\
\text { Space }\end{array}$ & $\begin{array}{l}\text { To ensure the integration } \\
\text { and inclusiveness of } \\
\text { urban spaces, creating } \\
\text { positive socio-economic } \\
\text { impacts on society }\end{array}$ & \\
\hline $\begin{array}{l}\text { Contractual } \\
\text { Space }\end{array}$ & $\begin{array}{l}\text { To enhance the values } \\
\text { of public goods, through } \\
\text { meeting common (social) } \\
\text { interests and needs for } \\
\text { urban space }\end{array}$ & $\begin{array}{l}\text { To ensure that newly created public } \\
\text { infrastructure, spaces, and services bring social } \\
\text { and economic vibrancy to local areas } \\
\text { To contribute to enhancing the condition of } \\
\text { existing publicly owned or managed spaces, } \\
\text { facilities, and services }\end{array}$ \\
\hline Dutiful Space & $\begin{array}{l}\text { To ensure the fair and } \\
\text { equitable distribution of } \\
\text { opportunities and benefits } \\
\text { (of mega urban projects) }\end{array}$ & $\begin{array}{l}\text { To improve accessibility to public transport and } \\
\text { opportunities, as well as regeneration effects at } \\
\text { a local scale } \\
\text { To improve accessibility to public transport and } \\
\text { opportunities as well as regeneration effects for } \\
\text { disadvantaged areas (of the studied areas) } \\
\text { To ensure negative environmental and social } \\
\text { externalities produced at a local level are } \\
\text { mitigated/ minimized; } \\
\text { To contribute to the obviation of economic and } \\
\text { social disparities (of the studied area) }\end{array}$ \\
\hline $\begin{array}{l}\text { Consequential } \\
\text { Space }\end{array}$ & $\begin{array}{l}\text { To foster the wide } \\
\text { distribution of benefits } \\
\text { contributing to the quality } \\
\text { of life of local people (of } \\
\text { the studied area) }\end{array}$ & $\begin{array}{l}\text { To ensure the outcome of mega urban projects } \\
\text { leads to improving the overall quality of } \\
\text { everyday life of local communities, by brining } \\
\text { positive change to both tangible and intangible } \\
\text { factors of social sustainability }\end{array}$ \\
\hline
\end{tabular}

\section{APPLICATION OF THE SPATIAL ETHICS MULTI-CRITERIA ASSESSMENT: A CASE STUDY OF CANNING TOWN}

This chapter introduces the case study to which the SE MCA is applied. It focuses on urban transport projects such as tubes and DLRs in East London with primary objectives including the regeneration of the area, and which have seen differential impacts from the spatial perspective since MUTI projects. The illustration of such steps is presented below in Figure 2. 


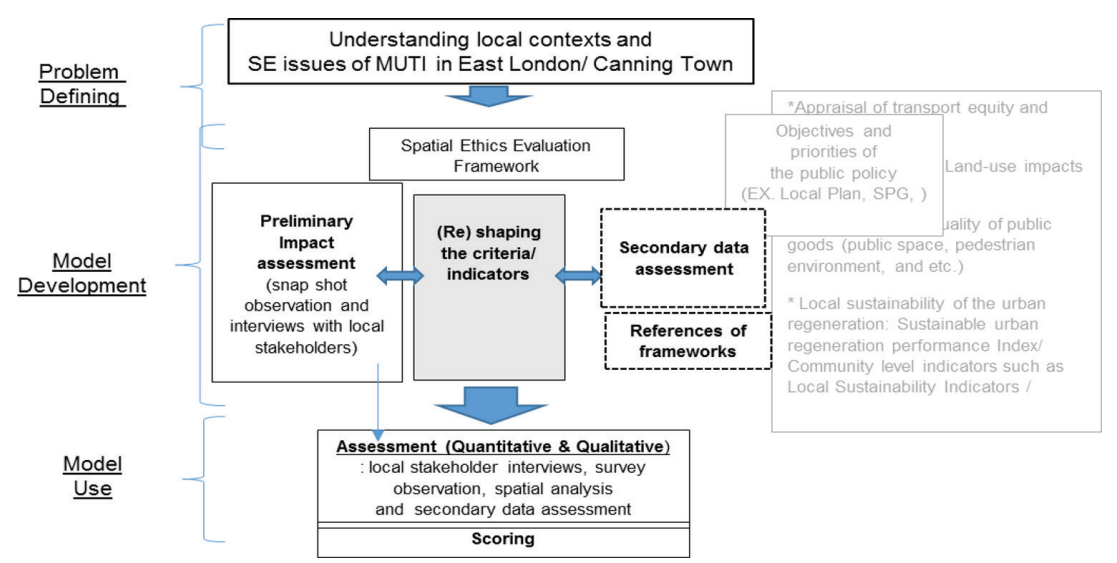

Figure 2: A process of application of SE MCA for the case study.

3.1 Setting the context: impacts of transport investment for urban regeneration of East London and Canning Town regeneration

East London suffered between the 1960s and 70s when the Docklands area was unable to compete with new container ports resulting in its rapid decline, and the emergence of associated social issues. However, more recently central and local government have put in much effort to regenerate the area identifying it as London's major source of brownfield land with significant capacity for new housing, commercial space and other development. Transport development and improvement efforts have been an important part of the regeneration of East London [20]. Firstly, the DLR opened in 1987 to secure the transport necessary to realize the potential of the public investment made to date by the London Docklands. The Jubilee Line Extension (JLE) was opened in 1999 to create a better link from the East to the West, contributing to economic growth and job opportunities, as well as increasing accessibility to opportunities in London. Further investments in DLR extension from Canning Town to Stratford were completed in 2011 to maximize the effect of the Olympic Legacy.

The transportation investments have been considered successful in terms of ultimate passenger numbers attracted and its contribution to supporting the further initiatives of Canary Warf development; however, it is not clear if impacts at micro scale met the various needs of local areas along the corridors [10]. In particular, it is questionable how much the local areas such as Canning Town benefit from the MUTI projects in East London, which, even in recent years, have shown the high level of deprivation in contrast with its neighbour areas such as Canary Wharf and Stratford [10]. In Caning Town, local people have had difficulties in accessing infrastructures and services, and lack a direct daytime bus route to the West End of London. The area has become transitory, and crime rates have been persistently high compared to other parts of London.

In this condition, regeneration initiatives took place in 2004 when Newham Council adopted the Master Plan of Canning Town Regeneration to improve the overall socio-economic situation, as well as the condition of the physical environment. The major projects included the mixed-use development at the catchment areas of Canning Town underground station, market redevelopment of a new town centre and the re-development of the most deprived residential 
area and upgrading a public school. Notably, the regeneration programme is an on-going project and many of the objectives are long-term and will be delivered incrementally through three phases.

\subsection{Building the SE MCA framework for the case study}

SE MCA framework is shaped with the secondary data assessment and a preliminary impact assessment (i.e. observations and interviews with local stakeholders). Notably, the reshaping process is not linear but progressive and recursive as the impact assessment proceeds.

\subsubsection{Preliminary assessment}

SE MCA framework has been shaped with the secondary data assessment and a preliminary impact assessment using the snapshot observations and interviews with local stakeholders to identify any missing measures to assess spatially differential impacts at local level as well as to obtain qualitative information as an input for the impact evaluation. Semi-structured local interviews investigated the long-term impacts perceived by local people with various profiles living in different locations in the studied area.

\subsubsection{Results and reshaped SE MCA framework}

Overall, the assessment identifies differential impacts over space, as well as the long-term impacts at the micro scale. As a result, the SE MCA framework (Table 1) has been reshaped clearly and properly articulated so as to enable quantitative and qualitative assessment with simple and easily understandable and measurable indicators (see Table 2)

The result of preliminary assessment (re) shapes the SE MCA framework. Firstly, the extent to which existing public infrastructure is preferred by local residents over the newly created public infrastructure needs to be investigated in order to identify the opportunities costs. Secondly, the quality of newly created public infrastructure and the quantity of those should be measured separately as the observation identify that the private sectors' contribution for public infrastructure mainly met the planning requirements in term of quantity. In addition, negative intermediate impacts at the local scale, and certain temporal negative externalities need to be reflected in the SE MCA framework. Importantly, the criteria of Consequential Space should assess both changes in the areas and its impact on the everyday lives of local people. Moreover, some indicators and criteria need to be re-identified through further research on alternative options as they are not relevant to the local context and/or requires data/ information which are not available or have been collected irregularly. In addition, impacts that are yet to be felt need to be distinguished from impact as of now, and the corrective evaluation needs to adopt longterm monitoring.

\subsection{Model application}

Both qualitative and quantitative assessments were conducted to assess long-term impact across the four dimensions of SE MCA. First of all, observation was conducted at several places, which were visited regularly at three different times of the day (9-10 AM, 1-2 PM, and 5-6 PM) both during weekdays and weekends. Secondly, in-depth interviews with relevant stakeholders, such as a real estate agency and regeneration officers, were conducted. The results of the preliminary assessment and the in-depth interviews provide critical inputs into overall evaluation, reflecting multi-scale interests in the mega urban projects. Moreover, 


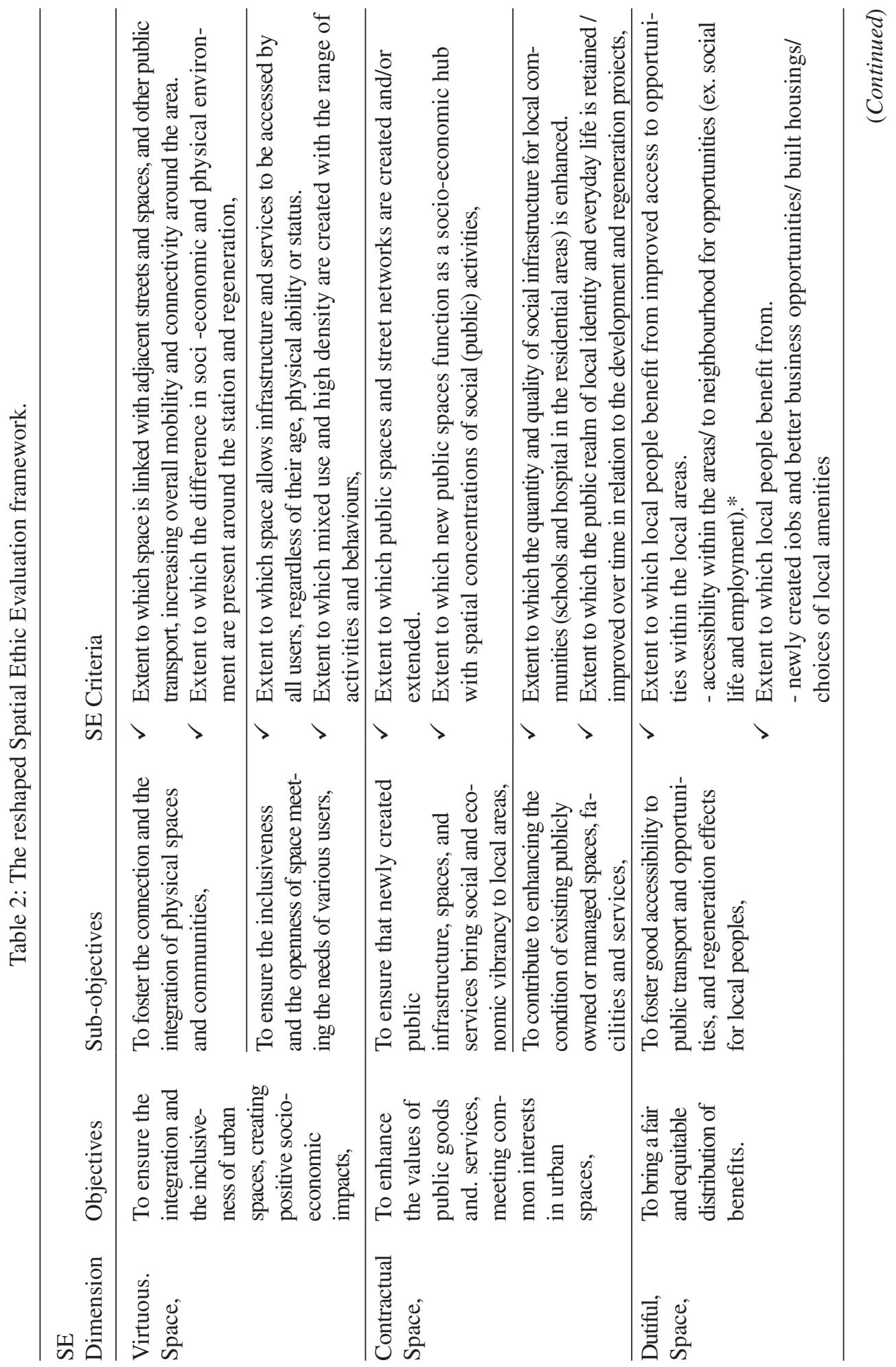




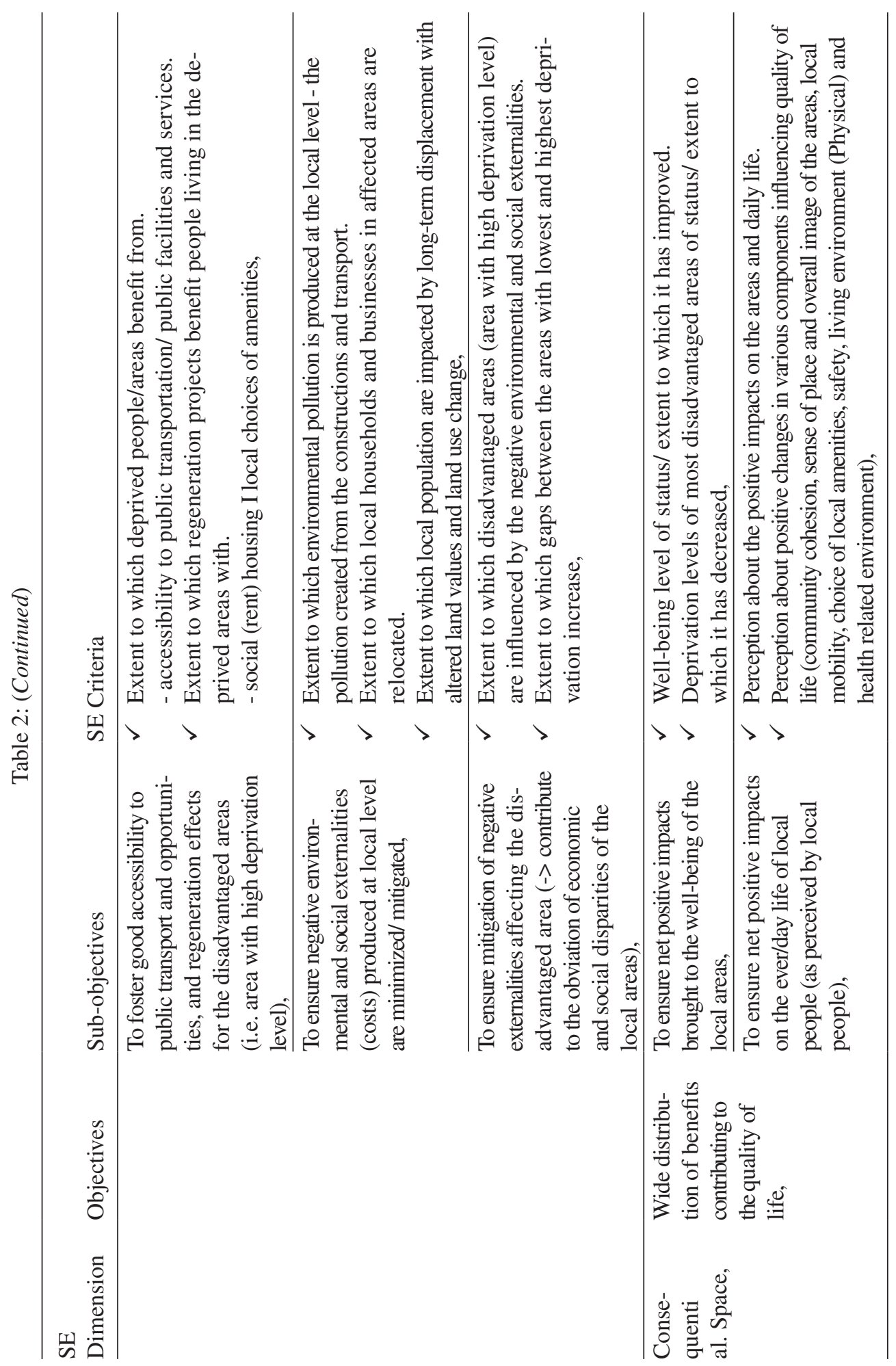




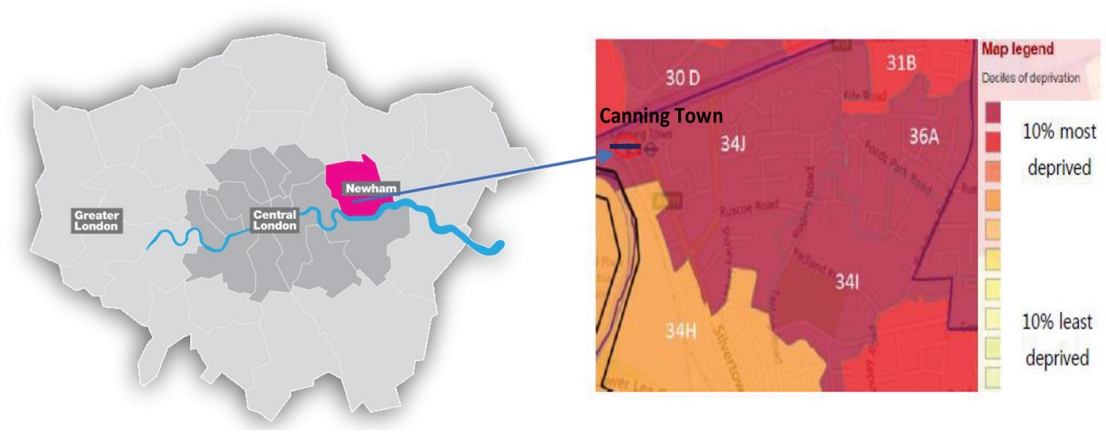

Figure 3: Integrated deprivation level of Canning Town in 2015 (Source: IMD, 2015).

the desk-based assessment was based on collecting and assessing government published data and regularly conducted research and surveys for the borough, as well as key policy documents. Borough, ward (i.e. Canning Town South), and LSOA (Lower Layer Super Output Area) data were used to assess the impacts at multiple scales. In particular, LSOA data are used to identify the least deprived (i.e. $34 \mathrm{H}$ ) and the most deprived areas (i.e. 34 I and $36 \mathrm{~A}$ ) within the studied area to measure the equitable distribution of benefits and negative externalities (see Fig. 3). To identify changes over time, various time periods of data were used.

\subsubsection{Virtuous Space assessment: enhancing connection and integration of urban spaces}

The creation of the inter-change was perceived as an agent of change by interviewees, which made a great contribution to connecting Canning Town to the rest of London. During the observation and the stakeholder interviews, Good levels of connectivity between the station and Canning Town were identified with the pedestrian and cycling passages which were developed during both the Jubilee Line extension and the catchment area regeneration. However, physical severances were created over time by the Rathbone market regeneration, which blocks the previous public passage between the public markets square and the station, while new residential buildings at the catchment areas block the whole view towards Canning Town from the station, separating residential areas from the public transport interchange and high streets. The issues of spatial differentiation were well observed, in particular, in terms of land-use and the quality of built environment between the station catchment areas and the rest of town. Although mixed-use development has been planned at the catchment areas, high-end residential developments dominate the corridors.

\subsubsection{Contractual Space assessment: enhancing the values of public goods meeting common interest}

Since the Jubilee Line Extension, the interchange plays a role as a public space. However, the newly created public spaces adjacent to the station do not appear to function as socio-economic hubs. Notably, minimal adherence of private sectors to their planning obligations has led to negative outcomes such as much lower level of socio-economic activities in comparison with before, due to the reduced size and the poor quality of regenerated public spaces (i.e. the Rathbone Market). In addition, in the residential areas, community activities are rarely observed at the newly created public spaces while the existing public spaces in the 
non-regenerated area were fully used by local communities despite their poor quality. Some positive impacts are also noted. Local communities were present and fully use the spaces at the upgraded primary school, and the recreational playground in the most deprived areas.

3.3.3 Dutiful Space assessment: fair and equitable distribution of benefits and burden.

First of all, local accessibility to public transport remains poor although accessibility to neighbourhood areas is rated as good. Half of local population in Canning Town South still have poor accessibility to the public transport [21] while accessibility to the major town centres in neighbourhoods such as Stratford, Barking, Canary Wharf, and East Ham improves: travel takes less than 20-30 minutes to the centres. It is not easy to identify the extent to which the JLE and the regeneration projects have brought benefits to locals, apart from the increased accessibility to neighbourhood and improved quality of the built environment in the regenerated areas. Notably, although the housing density of the area has increased, many of the new homes have been occupied by newly arrived people, rather than local people who were resident before the regeneration project started.

Secondly, it is noted that most areas with poor accessibility to public transportation are highly deprived areas. On average, $98 \%$ of the local population living in the areas of high deprivation (i.e. $36 \mathrm{~A}$ and $34 \mathrm{I}$ at the scale of LSOA) has poor accessibility to public transportation [21]. As most of people who currently benefit from the new housing and upgraded living environments are those new comers, it is difficult to define the extent to which people living in the disadvantaged area have benefited from the regeneration. Moreover, although the regeneration project is set to provide $35 \%$ affordable housing, approvals of projects are much less well aligned with these targets.

Thirdly, displacement due to the transport development is limited while most local businesses have been replaced by residential blocks, and tenants who used to live in the most deprived areas have been relocated. Notably, the local authorities emphasized that it is mainly housing policy change and overall welfare reform, which play the key role in making people leave the area rather than the regeneration programme. One important finding is that unexpected costs could be incurred due to the weak level of environmental impact mitigation (i.e. the dust from construction). It is noted that the areas which are most exposed to the pollution include those with the highest levels of deprivation: the areas with the least accessibility to the public transport as well as the highest levels of deprivation are located along the A13. In addition, the difference in household income level between the area along the corridors and the areas with high deprivation groups has increased gradually since 2001, which hints that the socio-economic disparity in the studied area has increased since 2001 .

\subsubsection{Consequential Space assessment: outcome enhancing the quality of life.}

It appears that although the well-being status of Canning Town South has increased since 2001 , the overall level is far under the welling-being stage. The community survey shows that $41 \%$ of interviewees saw positive changes in their daily life. Positive impacts were reported most frequently by the local business community on the high streets and all the residents who recently moved (back) to the regenerated residential areas. Negative changes were recognized by local businesses in the residential areas, and local communities whose jobs/employment opportunities have been affected, and the long-term residents complaining about the need to travel further for amenities. A few long-term residents saw no changes in their daily life while perceiving negative changes in Canning Town. Notably, 
locals perceive negative changes in terms of community cohesion, local mobility, choice of local amenities and the sense of place while seeing positive changes in safety and living (built) environment.

\subsubsection{Scoring based on the assessment}

The scoring was completed by the researcher based on the results from the qualitative and the quantitative assessment. Some of key points from the results will be discussed in the following chapter. In addition, pilot scoring and weighting was undertaken by the planning officer. The highest level of importance was given to the sub-objectives of mitigating the negative environmental externalities, followed by connection and integration of physical spaces and communities. The social externalities related objective was given the least importance. The results of scoring exercise show some similar and different opinions on the impacts between that of the researcher, as presented above. Overall, the long-term impact is rated much more positively by the officer than the one conducted by the researcher.

\section{DISCUSSION AND CONCLUSION}

Following discussion will reflect on the main findings of the research, concerning the longterm impact of mega infrastructure investments with respect of Spatial Ethics.

\subsection{Urban spatial transformation and public (social) benefits}

On basis of this SEE it can be concluded that The MUTI and urban regeneration projects produce spatial transformations, reflecting the market driven macro scale interests and a reliance on private sector for infrastructure investment. At the macro scale, differential outcomes are noted between the spatially selective areas of strategic importance and other places, which has continued to remain deprived over the long term. At the micro scale, socio-economic disparity is visible in the physical difference between the corridors/catchment areas and other parts of the local area. Notably, although MUTI has resulted in good accessibility to opportunities to some extent, regeneration projects can decrease pedestrian mobility through poorly integrated designs blocking public passage, while the need to travel further to neighbourhood areas is increased by the loss of local amenities.

The contribution of the MUTI for enhancing public goods and meeting social interests is not clear, while regeneration projects bring identifiable negative impacts on public benefits of local areas. Some public infrastructures and public spaces, which had previously played key social and economic roles in the local area, were pushed aside for more competitive uses. Such loss is even more apparent where the overall contribution of newly created social infrastructure is lower than the benefits brought by the enhancement of existing public facilities. As identified in the case study, The tendency of the private sector towards minimal adherence to the planning obligations also leads to negative outcomes. Moreover, the quality of life of residents and business communities are further exacerbated since most of the projects developed for enhancing public facilities are typically phased in the final stages of regeneration.

\subsection{Differential spatial impacts and the Golden Rules}

As Levinson ([6]) argues, current infrastructure planning practices contain biases and distortions that tend to be both horizontally and vertically inequitable. Differential levels of 
accessibility to the urban transport infrastructure are evident across the case study areas. In fact, the more negative community effects are concentrated within particular geographical locations, particularly within the areas of high deprivation. The area with the highest deprivation, is also the locality with the least accessibility to public transport as well as the most exposure to environmental and social risks from various projects. As such, the contribution of MUTI to the obviation of economic and social disparities is limited, and in fact the project reinforces the effect of deprivation and the inequalities arising from the socio-spatial division.

However, the generalization of the impact of regeneration/ MUTI on equity needs to be reconsidered. It is important to note that negative impacts are perceived differently by the diverse local communities, depending on many factors such as location, tenure type, and occupation. Moreover, factors influencing individual levels of resilience, such as health, education, and income status, are strongly related to the extent to which local people accrue benefits or are influenced by changes. It is also noted that some locals choose not to come back post- development due to changes in family structure or little attachment to the deprived areas, while others get displaced due to external factors such as housing benefit reforms. Fundamentally, some detrimental impacts are directly related to macro factors such as reforms to the social welfare policy as well as socio-demographic changes at the macro level.

\subsection{Impacts from a utilitarian perspective: who wins and who loses?}

A final question to be asked is whether the benefits of the MUTI project exceed the costs ultimately, contributing to, or detracting from, the quality of life of members of society over different space. Mega urban projects may bring improvement that does not even make society better off as a whole due to multiple negative impacts and limited regeneration effects. As identified in the case study, At local scale, it appears that the MUTI did not make contribution to the obviation of economic and social disparities while the ultimate impacts on the quality of life of the local is unclear, leaving the question on the ultimate winners of the local areas unsolved. In addition, the additional costs, which could be incurred by the negative environmental impacts that have not been actively mitigated could burden public sectors and the society as a whole. However, at the wider level, the positive impacts from the perspectives of boroughs in East London, can be considered: people who benefit from the affordable housing policy and increasing accessibility by moving from the East London or further areas, also the beneficiaries of transport investment and the regeneration scheme. Moreover, the stakeholders with the macro interests could be also beneficiaries in terms of the achievement of housing-led regeneration projects, which lead to increasing the economic values of urban space ultimately.

\section{REFERENCES}

[1] Miller, D. \& Patassini, D., Beyond benefit cost analysis: accounting for non-market values in planning evaluation, Ashgate, 2005.

[2] OMEGA Centre., Lessons for Mega Transport Project Developments and the Future of UK Cities and Regions. Final Report, OMEGA Centre, London: University College London, 2015.

[3] Booth, P., The Unearned Increment: Property and the Capture of Betterment Value in Britain and France. Lincoln Institute of Land Policy, Cambridge, MA, 2012. 
[4] Hoekveld, G. \& Needham, B., Planning practice between ethics and the power game: making and applying an ethical code for planning agencies. International Journal of Urban and Regional Research, 37(5), pp. 1638-1653, 2013. (Oxford: John Wiley \& Sons Ltd, 2013). https://doi.org/10.1111/j.1468-2427.2012.01146.x

[5] Graham, S. \& Marvin, S., Splintering Urbanism: Networked infrastructures, technological motilities and the urban condition. Routledge: London, 2001.

[6] Levinson, D., Identifying winners and losers in transportation. Transportation Research Record: Journal of the Transportation Research Board, 1812, pp. 179-185, 2002. https://doi.org/10.3141/1812-22

[7] Beyazit, E., Evaluating social justice in transport: lessons to be learned from the capability approach. Transport Review, 31(1), pp. 117-134, 2010. https://doi.org/10.1080/01441647.2010.504900

[8] Litman, T., Well Measured: Developing Indicators for Comprehensive and Sustainable Transport Planning, Victoria Transport Policy Institute, 2008. Available at: www.vtpi. org/wellmeas.pdf. (Accessed 25 August, 2016).

[9] Kaparos, G., Skayannis, P. \& Pavleas, S., Athens Metro Project Profile, OMEGA Research Programme Study Report, Department of Planning and Regional Development, University of Thessaly, Volos, 2010.

[10] Jones, P., Assessing the wider impacts of the Jubilee Line Extension in East London. Chapter 21 in Hickman, R., Givoni, M., Bonilla, D. \& Banister, D. (eds). An International Handbook on Transport and Development. Edward Elgar, 2010.

[11] Martens, K., Basing transport planning on principles of social justice. Berkeley Planning Journal, 19, pp. 1-7, 2006.

[12] Colantonio, A., The Social Sustainability Assessment Framework, presented at OISD - EIB. Workshop on Social Sustainability and Urban Regeneration in EU Cities, pp. 19-20 Oxford Institute for Sustainable Development, 2009.

[13] Fisher, T., Spatial ethics. The Ethical Design of Places, 40, pp. 152-157, 2009.

[14] Priemus, H., Flyvbjerg, B. \& van Wee, B. (eds.), Decision-making on Mega-Projects: Cost-Benefit Analysis, Planning and Innovation. Edward Elgar, Cheltenham, UK and Northampton, MA, 2008.

[15] Rydin, Y., Governing for sustainable urban development. Earthscan, London, 2010.

[16] New Economic Foundation (NEF), Measuring Real Value: a DIY Guide to Social Return On Investment. London, 2007.

[17] Burdge, R. \& Vanclay, F., Social impact assessment: a contribution to the state of the art series. Impact Assessment, 14(1), pp. 59-86, 1996. https://doi.org/10.1080/07349165.1996.9725886

[18] Van Schooten, M, Vanclay, F. \& Slootweg, R., Conceptualising Social Change Processes and Social Impacts. In H Becker \& F Vanclay (eds.), The International Handbook of Social Impact Assessment: Conceptual and Methodological Advances, pp. 74-91, Edward Elgar. Cheltenham, UK, 2003.

[19] Davoudi, S. \& Healey, P., City Challenge: sustainable process or temporary gesture? Environment and Planning C: Government and Policy, 13(1), pp. 79-95, 1993. https://doi.org/10.1068/c 
[20] Hall, P. \& Hickman, R., Moving the city east: explorations into contextual public transport-oriented. Development Planning Practice \& Research, 23(3), pp. 323-339, 2008. https://doi.org/10.1080/02697450802423583

[21] Transport for London. Public Transport Accessibility Level. Available at: https://tfl.gov. uk/info-for/urban-planning-and-construction/planning-with-webcat/webcat. (Accessed July 28, 2016). 